\title{
Pengaruh Orientasi Kewirausahaan, Kinerja Pemasaran, dan Kapabilitas TIK Terhadap Keunggulan Bersaing Pada Pelaku UMKM di Sentra Industri Sepatu Cibaduyut Kota Bandung.
}

\author{
Mochammad Rifky Pamungkas ${ }^{1 *}$, Muhamad Rizal ${ }^{2}$, Ria Arifianti ${ }^{3}$, Asmaul Husna ${ }^{4}$ \\ ${ }^{1,2,3}$ Universitas Padjadjaran, Kota Bandung, Jawa Barat, Indonesia \\ ${ }^{4}$ Universitas Maritim Raja Ali Haji, Kota Tanjungpinang, Kepulauan Riau, Indonesia
}

\begin{abstract}
ABSTRAK : Covid-19 merambah masuk ke Indonesia memberikan dampak terhadap Usaha, Mikro Kecil dan Menengah (UMKM). Salah satu UMKM yang terimbas pandemi Covid-19 ialah Sentra Industri Sepatu Cibaduyut. Hal tersebut berdampak pada bisnis, pemasaran, informasi dan daya bersaing para pelaku UMKM di Cibaduyut. Maka tujuan penelitian ialah untuk mencari serta mengetahui pengaruh orientasi kewirausahaan, kinerja pemasaran, serta kapabilitas TIK terhadap keunggulan bersaing. Metode penelitian yang digunakan ialah kuantitatif dengan sampel penelitian ialah pelaku UMKM di Cibaduyut dan analisis dengan Structural Equation Modeling-Partial Least Square. Sedangkan hasil penelitian memberikan hasil untuk pengaruh terbesar berada pada variabel kapabilitas TIK sebesar 44,9\%. Kesimpulan dalam penelitian ini ialah variabel orientasi kewirausahaan dan kinerja pemasaran tidak berpengaruh signifikan terhdap keunggulan bersaing sedangkan variabel kapabilitas TIK berpengaruh signifikan.
\end{abstract}

Kata kunci: Orientasi kewirausahaan; Kinerja pemasaran; Kapabilitas TIK; Keunggulan bersaing; Structural Equation Modeling.

\begin{abstract}
Covid-19 penetrates into Indonesia to have an impact on Business, Micro, Small and Medium Enterprises (MSMEs). One of the MSMEs affected by the Covid-19 pandemic is the Cibaduyut Shoe Industry Center. This has an impact on business, marketing, information and the competitiveness of MSME players in Cibaduyut. So the research objective is to find and determine the effect of entrepreneurial orientation, marketing performance, and ICT capabilities on competitive advantage. The research method used is quantitative with the research sample being SMEs in Cibaduyut and analysis using Structural Equation Modeling-Partial Least Square. While the results of the study provide results for the greatest influence on the ICT capability variable of $44.9 \%$. The conclusion in this study is that the entrepreneurial orientation variable and marketing performance do not have a significant effect on competitive advantage, while the ICT capability variable has a significant effect.
\end{abstract}

Keywords: Entrepreneurial orientation; Marketing performance; ICT capabilities; Competitive advantage; Structural Equation Modeling.

Email Address : $\underline{\text { moch20015@mail.unpad.ac.id }}{ }^{1}, \underline{\text { muhamad.rizal@unpad.ac.id }}^{2}, \underline{\text { r.arifianti@unpad.ac.id }}{ }^{3}$, asmaulhusna@umrah.ac.id ${ }^{4}$

\section{Pendahuluan}

Awal mula Covid-19 masuk ke Indonesia sampai saat ini memberikan dampak pada sektor ekonomi salah satunya dampak terhadap Usaha Mikro, Kecil dan Menengah (UMKM) (Suryani, 2021). UMKM bagi negara 
berkembang menjadi salah satu tumpuan untuk perekonomian dan memberikan kontribusi bagi penciptaan lapangan pekerjaan (Singh, 2011). Imbas pandemi Covid- 19 terhadap UMKM bisa dilihat dari sisi penawaran serta sisi permintaan (Febrantara, 2020). Salah satu UMKM yang terdampak oleh Covid-19 ialah para pelaku usaha di Sentra Industri Sepatu Cibaduyut. Menurut Cahyono (2020) para pelaku UMKM di Cibaduyut mengalami penurunan omzet yang sangat drastis karena sangat minimnya penawaran dan permintaan dari para konsumen.

Sentra Industri Sepatu Cibaduyut awal dikembangkan sekitar tahun 1978 dan masih berdiri hingga saat ini. Sentra Industri Sepatu Cibaduyut ini merupakan salah satu dari sentrasentra industri dan perdagangan di Kota Bandung yang menjadi fokus program pemerintah Kota Bandung untuk terus dikembangkan. Berdasarkan data Dinas Perdagangan dan Perindustrian (Disdagin) Kota Bandung sampai tahun 2020 ada sekitar 517 pelaku UMKM didalamnya (Disdagin Kota Bandung, 2020).

Sentra Industri Sepatu Cibaduyut secara lokasi bertempat di Kecamatan Bojongloa Kidul Kelurahan Cibaduyut yang sebagian penduduknya bermata pencaharian utama terletak pada bagian perdangangan serta pengusaha dengan presentase $21.29 \%$ dan industri sebesar $25.34 \%$. Area sekitar Sentra Industri Sepatu Cibaduyut ini memanglah mempunyai kemampuan ekonomi dalam zona industri serta perdagangan, sebab sebagian besar tenaga kerja terserap di kedua zona tersebut. Spesialnya pada pada sentra industri kecil menengah pembuatan sepatu, perdagangan sepatu, dan perdagangan oleh- oleh khas Bandung.

Tetapi selama berdirinya Sentra Industri Sepatu Cibaduyut hingga saat ini dan juga ditambah merambahnya pandemi Covid-19, permasalahan yang nyata dihadapi ialah situasi pasang surut yang disebabkan oleh prioritas konsumen. Karena jaman sekarang mayoritas sudah lebih menyenangi sepatu dengan merekmerek ternama dari luar negeri ketimbang sepatu handmade atau sepatu-sepatu dari produk dalam negeri khususnya sepatu hasil Sentra Industri Sepatu Cibaduyut. Hal tersebut berpengaruh pada lemahnya daya saing para pelaku usaha di Sentra Industri Sepatu Cibaduyut (Fiqih, 2016). Permasalahan lainnya yang yaitu disebabkan oleh persepsi atau pemikiran dari para pelaku UMKM yang selalu merasa puas dengan apa yang dilakukan dan dimiliki saat ini, sehingga minimnya pemikiran untuk menjadikan usaha bisnisnya terus berkembang.

Kendala umum yang dihadapi para pelaku UMKM dalam mencapai keunggulan bersaing dan pencapaian kinerja mereka ialah (i) terbatasnya terhadap akses permodalan,( ii) terbatasnya terhadap akses ke pasar, serta( iii) terbatas akses data menimpa sumberdaya serta teknologi (Susilo, 2010). Berdasarkan situasi dan kondisi yang dihadapi para pelaku UMKM di Sentra Industri Sepatu Cibaduyut yaitu dampak Covid-19 dan juga masih lemahnya daya saing disana, menurut Porter (1994) dijelaskan bahwa untuk meningkatkan keunggulan bersaing atau memiliki daya saing salah satunya yaitu dengan mempertimbangkan teknologi, jiwa entrepreneurship, serta pemasaran yang meluas dan agresif.

Menurut penelitian Drucker (1994) dalam dunia usaha yang nyata agar dapat memiliki keunggulan bersaing dibutuhkan Karakter dan karakteristik seseorang untuk mewujudkan gagasan inovatifnya, hal tersebut dinamakan orientasi kewirausahaan.

Menurut Avlontis \& Salavou (2007) orientasi kewirausahaan merupakan fenomena organisasi yang mencerminkan kemampuan manajemennya, dimana perusahaan mulai berinisiatif dan mengubah perilaku bersaingnya, sehingga dapat memperoleh keuntungan dari usaha yang dijalankan dan dikembangkannya. memiliki sifat keunggulan bersaing. Menurut Lumpkin \& Dess (1996) orientasi kewirausahaan memiliki beberapa indikator yang berpengaruh 
positif signifikan terhadap keunggulan bersaing (H1).

Menurut penelitian Ferdinand (2000) Strategi perusahaan selalu berorientasi pada menghasilkan penjualan, pangsa pasar, dan pertumbuhan penjualan. Kinerja pemasaran dapat dikatakan variabel yang fundamental untuk mengukur dan menilai sejauh mana kinerja pemasaran itu dicapai, dengan memperhatikan beberapa indikator yaitu omzet penjualan, wilayah pemasaran, sales return, dan peningkatan penjualan (Ferdinand, 2002). Perusahaan memiliki kepentingan untuk mengetahui lebih jauh prestasi pasar dari produk atau jasa yang dipasarkannya dengan tujuan sebagai acuan dari keberhasilan bisnisnya agar memiliki daya kolaborasi maupun keunggulan bersaing dengan kompetitor lainnya (Wibowo, 2006). Menurut Ferdinand (2002) kinerja pemasaran merupakan variabel yang berpengaruh positif signifikan terhadap keunggulan bersaing $(\mathrm{H} 2)$.

Menurut penelitian Zhang, et al (2008) untuk dapat memiliki sifat keunggulan bersaing, memiliki kemampuan teknologi informasi adalah sebuah keharusan bagi perusahaan dalam memobilisasi dan menyebarkan sumber daya yang dimiliki dengan berlandaskan teknologi informasi yang dikolaborasikan ataupun digabungkan dengan sumber daya dan berbagai kemampuan lainnya. Menurut Deeson (1991) Teknologi Informasi serta Komunikasi (TIK) ialah kebutuhan manusia di dalam mengambil serta memindahkan, mencerna serta memproses data dalam konteks sosial yang menguntungkan diri sendiri serta warga secara totalitas.

Menurut Zultaqawa (2020) dengan memiliki, menggunakan dan memanfaatkan TIK, keunggulan bersaing dari perusahaan tersebut sangat dapat merespon perubahan lingkungan yang terjadi sehingga perusahaan dapat meningkatkan keuntungan, fokus terhadap pelanggan dengan layanan yang maksimal, meningkatkan kualitas dan produktivitas perusahaan, mengorganisir proses bisnis perusahaan, serta memunculkan strategi-strategi keterbaruan untuk memproduksi produk atau jasa, dan juga mendatangkan relasi-relasi ataupun aliansi bisnis serupa. Ada beberapa indikator kapabilitas TIK dari penelitian Sutisna (2012) yang memiliki pengaruh positif signifikan terhadap keunggulan bersaing ialah akses, tata kelola, integrasi, evaluasi, dan menciptakan (H3).

Berdasarkan fenomena dan teori-teori yang telah dibahas sebelumnya maka tujuan dalam penelitian ini adalah untuk mengetahui pengaruh orientasi kewirausahaan, kinerja pemasaran, dan kapabilitas TIK terhadap keunggulan bersaing dari para pelaku UMKM di Sentra Industri Sepatu Cibaduyut.

\section{Metode Penelitian}

Metode penelitian ini menggunakan jenis penelitian kuantitatif. Penelitian ini dilakukan di Sentra Industri Sepatu Cibaduyut Kota Bandung dengan fokus pada pelaku UMKM pada sektor industri dan perdagangan. Instrumen penelitian menggunakan kuesioner berskala ordinar dengan model skala likert. Kuesioner berisikan pernyataan dan isian jawaban 1-5 (Sangat Tidak Setuju, Tidak Setuju, Netral, Setuju, Sangat Setuju) yang kemudaian disebar kepada responden berdasarkan populasi di Sentra Industri Sepatu Cibaduyut sebanyak 517 pelaku UMKM dan mengambil jumlah sampel menggunakan rumus Slovin dengan tingkat eror $10 \%$. Tahapan pengolahan data dan analisis data dengan melakukan uji validitas, uji reliabilitas, serta uji model pengukuran dan struktural dengan menggunakan Structural Equation Modeling-Partial Least Square (SEMPLS).

\section{III.Hasil dan Pembahasan}

Hasil dan pembahasan pertama yang dilakukan ialah menjelaskan hasil uji validitas dan juga uji reabilitas. Uji validitas dan reliabilitas ini dilakukan pada variabel penelitian 
yaitu untuk variabel bebas orientasi kewirausahaan (X1), kinerja pemasaran (X2), dan Kapabilitas TIK (X3) sedangkan variabel terikatnya yaitu keunggulan bersaing (Y).

Uji validitas menurut Malhotra (2009) dikatakan valid apabila rhitung > rtabel $(0,361)$. Uji validitas ini dilakukan untuk mencari tahu bahwa item pernyataan dalam kuesioner yang disebar memiliki kelayakan atau tidak. Sedangkan uji reliabilitas menurut Sekaran (2003) diukur dengan menggunakan nilai Cronbach's Alpha, nilai reliabilitas $<0.60$ dinyatakan kurang baik, 0.70 dinyatakan dapat diterima, dan $>0.80$ dinyatakan baik. Uji reliabilitas pun dilakukan untuk mengukur sejauh mana item pernyataan kuesioner penelitian memiliki kekuatan. Berikut adalah hasil untuk uji validitas dan reliabilitas dijelaskan melalui Tabel 1 dan 2.

Tabel 1 Hasil Uji Validitas Variabel

\begin{tabular}{|c|c|c|c|c|}
\hline \multirow{4}{*}{ Variabel } & \multirow{2}{*}{$\begin{array}{c}\text { Kode } \\
\text { item }\end{array}$} & \multicolumn{3}{|c|}{ Validitas } \\
\cline { 2 - 5 } & & & rhitung & Keterangan \\
\hline \multirow{4}{*}{$\begin{array}{c}\text { Orientasi } \\
\text { Kewirausahaan } \\
\text { (X1) }\end{array}$} & X1.1 & 0.852 & 0.361 & Valid \\
\cline { 2 - 5 } & X1.2 & 0.883 & 0.361 & Valid \\
\cline { 2 - 5 } & X1.3 & 0.827 & 0.361 & Valid \\
\cline { 2 - 5 } & X1.4 & 0.709 & 0.361 & Valid \\
\cline { 2 - 5 } & X1.5 & 0.887 & 0.361 & Valid \\
\hline \multirow{4}{*}{$\begin{array}{c}\text { Kemerja } \\
\text { Pemaran (X2) }\end{array}$} & X2.1 & 0.920 & 0.361 & Valid \\
\cline { 2 - 5 } & X2.2 & 0.880 & 0.361 & Valid \\
\cline { 2 - 5 } & X2.3 & 0.904 & 0.361 & Valid \\
\hline \multirow{4}{*}{$\begin{array}{c}\text { Kapabilitas TIK } \\
\text { (X3) }\end{array}$} & X3.1 & 0.802 & 0.361 & Valid \\
\cline { 2 - 5 } & X3.2 & 0.813 & 0.361 & Valid \\
\cline { 2 - 5 } & X3.3 & 0.766 & 0.361 & Valid \\
\cline { 2 - 5 } & X3.4 & 0.768 & 0.361 & Valid \\
\cline { 2 - 5 } & X3.5 & 0.611 & 0.361 & Valid \\
\hline \multirow{4}{*}{$\begin{array}{c}\text { Keunggulan } \\
\text { Bersaing (Y) }\end{array}$} & Y1.1 & 0.859 & 0.361 & Valid \\
\cline { 2 - 5 } & Y1.2 & 0.924 & 0.361 & Valid \\
\cline { 2 - 5 } & Y1.3 & 0.617 & 0.361 & Valid \\
\cline { 2 - 5 } & Y1.4 & 0.656 & 0.361 & Valid \\
\cline { 2 - 5 } & Y1.5 & 0.910 & 0.361 & Valid \\
\hline
\end{tabular}

Sumber: Data Diolah (2021)
Tabel 2 Hasil Uji Reliabilitas Variabel

\begin{tabular}{|l|c|c|}
\hline \multicolumn{3}{|c|}{ Reability Statistic } \\
\hline \multicolumn{1}{|c|}{ Variabel } & $\begin{array}{c}\text { Croncbach } \\
\text { Alpa }\end{array}$ & N of Items \\
\hline Orientasi Kewirausahaan (X1) & 0.878 & 6 \\
\hline Kinerja Pemasaran (X2) & 0.890 & 4 \\
\hline Kapabilitas TIK (X3) & 0.803 & 5 \\
\hline Keunggulan Bersaing (Y) & 0.843 & 5 \\
\hline
\end{tabular}

Sumber: Data Diolah (2021)

Berdasarkan Tabel 1 dan 2 dapat dijelaskan bahwa seluruh item pernyataan dalam kuesioner telah memenuhi syarat dengan seluruh nilainya berada berada diatas nilai rtabel $(0,361)$ dan dinyatakan valid, begitu pula dengan nilai reliabilitas berada diatas 0,7 dan dinyatakan reliabel.

Tahapan selanjutnya setelah melakukan uji validitas serta uji reliabilitas terhadap variabel yang digunakan dalam penelitian, selanjutnya masuk ke tahapan pengolahan data menggunakan Structural Equation ModelingPartial Least Square (SEM-PLS). Dalam SEMPLS proses yang pertama dilakukan ialah model pengukuran (outer model).

Ummi (2015) menjelaskan bahwa indikator akan dinyatakan reliabel apabila nilai korelasi $>0.70$. Tetapi pada pengembangan tahap riset, nilai loading factor 0,40-0,60 masih dapat diterima. Berikut adalah Gambar 1 dan Tabel 3 untuk rekapitulasi nilai loading factor dari setiap indikator.

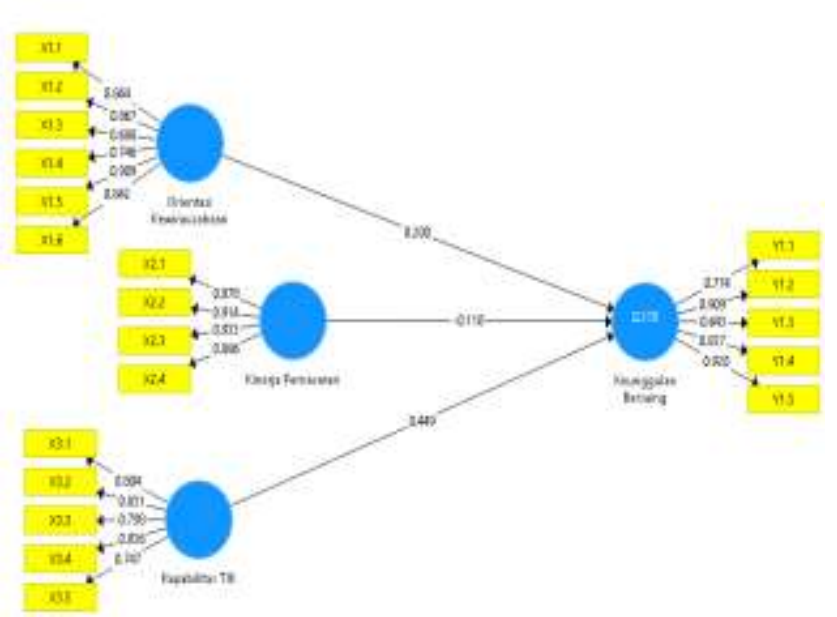

Gambar 1 Nilai Loading Factor

Sumber: Data Diolah (2021) 


\section{Tabel 3 Rekapitulasi Nilai Loading Factor}

\begin{tabular}{|c|c|c|}
\hline Variabel & Indikator & $\begin{array}{l}\text { Loading } \\
\text { Factor }\end{array}$ \\
\hline \multirow{6}{*}{$\begin{array}{c}\text { Orientasi } \\
\text { Kewirausahaan } \\
(X 1)\end{array}$} & $X 1.1$ & 0.844 \\
\hline & $\mathrm{X} 1.2$ & 0.867 \\
\hline & $\mathrm{X} 1.3$ & 0.688 \\
\hline & $\mathrm{X} 1.4$ & 0.746 \\
\hline & $\mathrm{X} 1.5$ & 0.909 \\
\hline & $X 1.6$ & 0.842 \\
\hline \multirow{4}{*}{$\begin{array}{c}\text { Kinerja } \\
\text { Pemasaran } \\
(\mathrm{X} 2)\end{array}$} & X2.1 & 0.878 \\
\hline & $\times 2.2$ & 0.914 \\
\hline & $\times 2.3$ & 0.933 \\
\hline & $\times 2.4$ & 0.886 \\
\hline \multirow{5}{*}{$\begin{array}{c}\text { Kapabilitas TIK } \\
\text { (X3) }\end{array}$} & X3.1 & 0.804 \\
\hline & $\mathrm{X} 3.2$ & 0.831 \\
\hline & X3.3 & 0.798 \\
\hline & X3.4 & 0.836 \\
\hline & $\times 3.5$ & 0.747 \\
\hline \multirow{5}{*}{$\begin{array}{l}\text { Keunggulan } \\
\text { Bersaing (Y) }\end{array}$} & Y1.1 & 0.774 \\
\hline & Y1.2 & 0.909 \\
\hline & Y1.3 & 0.643 \\
\hline & Y1.4 & 0.837 \\
\hline & Y1.5 & 0.920 \\
\hline
\end{tabular}

Sumber: Data Diolah (2021)

Hasil pada Gambar 1 dan Tabel 3 menunjukan bahwa indikator seluruhnya telah berada diatas nilai 0,4 , dan dinyatakan reliabel. Dalam model pengukuran terdapat tiga kriteria analisis data PLS melalui Average Variance Extracted (AVE), Cronbach Alpha dan Composite Reliability (Ghozali, 2008).

Tabel 4 Kriteria Analisis Model Pengukuran (Outer Model)

\begin{tabular}{|c|c|c|c|c|}
\hline Variabel & $\begin{array}{c}\text { Cronbach's } \\
\text { Atphin }\end{array}$ & tho $\mathrm{A}$ & $\begin{array}{l}\text { Composte } \\
\text { Reliability }\end{array}$ & $\begin{array}{c}\text { Average } \\
\text { Variance } \\
\text { Extracted (AVE) }\end{array}$ \\
\hline Onientasi Kewiralsahaan $(\mathrm{Xl})$ & 0.863 & 0.864 & 0.901 & 0.646 \\
\hline KineijaPemasaran $(\mathrm{X})$ & 0.878 & 0.912 & 0.912 & 0.677 \\
\hline Kapabilitas TIK (X3) & 0.925 & 0.936 & 0.946 & 0.815 \\
\hline Kennogylan Bersaing $(Y)$ & 0.902 & 0.924 & 0.924 & 0.672 \\
\hline
\end{tabular}

Sumber: Data Diolah (2021)

Berdasarkan Tabel 4 seluruh variabel telah memenuhi nilai untuk uji validitas dan reliabilitas konstruk yaitu cronbach's alpha >0.6, nilai AVE > 0.5, dan composite reliability > 0.7 . Maka dari itu penelitian ini proses pengolahan data dan analisisnya dapat dilanjutkan ke tahapan berikutnya yaitu analisis model structural.

Analisis model struktural dilakukan agar dapat memastikan bahwa model yang dibangun itu akurat. Evaluasi model struktural dapat diperhatikan dari kriteria-kriteria yang mencakup; koefisien determinasi $\left(\mathrm{R}^{2}\right)$; Predictive Relevance $\left(\mathrm{Q}^{2}\right)$; Goodness of Fit Index $(\mathrm{GoF})$.

Nilai koefisien determinasi $\left(\mathrm{R}^{2}\right)$ didapatkan berdasarkan hasil olah software SmartPLS 3.0 dengan memperhatikan nilai $R$-Square. Berikut dijelaskan melalui Tabel 5.

Tabel 5 Nilai Koefisien Determinasi $\left(\mathbf{R}^{2}\right)$

\begin{tabular}{|c|c|c|}
\hline Variabel & $R$ Square & $R$ Square Adjusted \\
\hline Keungoulan Bersaing $(\mathrm{Y})$ & 0.278 & 0.251 \\
\hline \multicolumn{3}{|c|}{ Sumber: Data Diolah (2021) }
\end{tabular}

Berdasarkan Tabel 5 didapatkan dari nilai $R$-Square sebesar 0.278, menurut Chin (1998) nilai $R$-Square $>0.19$ maka dikategorikan moderat, sehingga model penelitian ini termasuk kategori moderat. Untuk nilai Predictive Relevance $\left(\mathrm{Q}^{2}\right)$ didapatkan dari hasil perhitungan:

$$
Q^{2}=1-\left(1-R 1^{2}\right)\left(1-R 2^{2}\right) \ldots \ldots\left(1-R n^{2}\right)
$$

Berdasarkan rumus tersebut maka hasil $\mathrm{Q}^{2}$ didapatkan sebesar 0,772. Menurut Chin (1998), apabila nilai $\mathrm{Q}^{2}$ yang didapatkan $>0.35$ sehingga model mempunyai kapabilitas prediksi yang besar atau kuat. Untuk nilai Goodness of Fit Index (GoF) didapatkan dari hasil perhitungan: Diketahui:

$\mathrm{AVE}=((0.646+0.677+0.815+0.627) / 4)=0.692$ $\mathrm{R} 2=0.278$

Sehingga GoF dapat dihitung sebagai berikut:

$$
G o F=\sqrt{ } 0.6922 \times 0.278=0.365
$$

Menurut Tenenhaus et al., (2005) nilai GoF kecil di antara $0-0.25$, GoF sedang (moderat) di antara 0.25-0.36 dan GoF besar apabila >0.36. Dari hasil perhitungan nilai GoF hingga bisa dinyatakan bahwa model memiliki nilai GoF yang besar $>0.36$, dengan demikian model yang dibentuk dapat dilakukan pengujian hipotesis.

Pengujian hipotesis pada software SmartPLS 3.0 dicoba dengan proses bootstrapping buat menciptakan nilai $P$-Value. Apabila nilai $P$-Value lebih besar dari taraf signifikansi sebesar 5\% maka hipotesis dikatakan 
tidak berpengaruh signifikan $\mathrm{H} 0$ diterima, begitupun sebaliknya apabila $P$-Value lebih kecil dari taraf signifikansi 5\% maka $\mathrm{H} 0$ diterima. Berikut adalah model yang menggambarkan hasil bootstraping pada variabel yang digunakan dalam penelitian ini dapat dilihat pada Gambar 2.

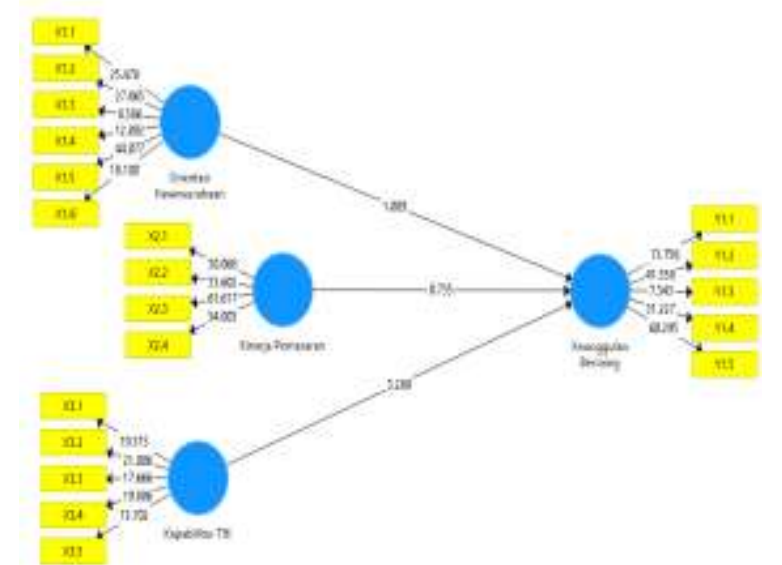

Gambar 2 Hasil Bootstrapping Model Penelitian Sumber: Data Diolah (2021)

Setelah hasil pengujian terhadap hipotesis diketahui maka berikutnya adalah mengetahui seberapa besar pengaruh di antara varabel-variabel penelitian. Untuk mengetahui hal itu berikut disajikan nilai loading factor output smartPLS, dijelaskan melalui Gambar 3.

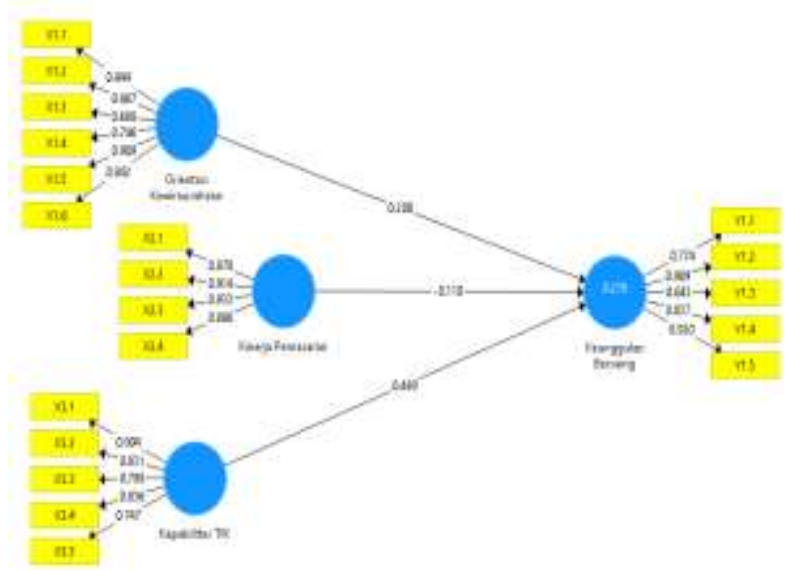

Gambar 3 Nilai Loading Factor

Sumber: Data Diolah (2021)

Gambar 3 menyajikan standardized solution pengaruh antar variabel. Nilai standardized solution variabel orientasi kewirausahaan terhadap keunggulan bersaing memiliki nilai sebesar 0,200. Langkah selanjutnya yaitu menganalisis koefisien jalur (path coeffiecients) dari masing-masing variabel bebas (X) terhadap variabel dependen (Y).

\section{Tabel 6 Koefiesien Jalur (Path Coefficients)}

\begin{tabular}{|l|c|c|c|c|c|}
\hline \multicolumn{1}{|c|}{ Hipotesis } & $\begin{array}{c}\text { Original } \\
\text { Sample } \\
(0)\end{array}$ & $\begin{array}{c}\text { Sample Mean } \\
(\mathrm{M})\end{array}$ & $\begin{array}{c}\text { Standard } \\
\text { Deviation } \\
\text { (STDEV) }\end{array}$ & $\begin{array}{c}\text { T Statistics } \\
\text { (O/STDEV) }\end{array}$ & P-Values \\
\hline $\begin{array}{l}\text { Orientasi Kewirausahaan (X1) -> } \\
\text { Keunggulan Bersaing (Y) }\end{array}$ & 0.200 & 0.202 & 0.132 & 1.089 & 0.277 \\
\hline $\begin{array}{l}\text { Kinerja Pemasaran (X2) -> } \\
\text { Keunggulan Bersaing(Y) }\end{array}$ & $-0,110$ & -0.116 & 0.146 & 0.749 & 0.454 \\
\hline $\begin{array}{l}\text { Kapabiltas TIK (X3) -> } \\
\text { Keunggulan Bersaing(Y) }\end{array}$ & 0.449 & 0.446 & 0.132 & 3.400 & 0.001 \\
\hline
\end{tabular}

Sumber: Data Diolah (2021)

Berdasarkan Tabel 6, output p-value diperoleh hasil bahwa hipotesis $\mathrm{H}_{1}$ dan $\mathrm{H} 2$ bernilai $p$-value di atas taraf signifikansi (5\%), itu bermakna memiliki pengaruh tidak signifikan terhadap variabel dependen (H01 dan $\mathrm{H} 02$ diterima). Hal tersebut mungkin dapat disebabkan oleh pandemi Covid-19 ini yang memudarkan pergerakan serta langkah para pelaku UMKM di Sentra Industri Sepatu Cibaduyut, sehingga mempengaruhi orientasi kewirausahaan dan kinerja pemasaran sebagian para pelaku UMKM disana dan berdampak pada lemahnya usaha di era pandemi Covid-19 ini karena semakin kebingungan bagaimana meningkatkan kembali performa usaha baik dari sisi produksi maupun dari pemasaran produknya.

Sedangkan untuk $\mathrm{H}_{3}$ memiliki pengaruh signifikan karena nilai $p$-value di bawah taraf signifikansi (5\%) yaitu $1 \%$ (H03 ditolak). Hal tersebut dapat saja disebabkan oleh situasi dimana di era pandemi Covid-19 ini orang-orang kebanyakan mengakses segala informasi menggunakan internet ataupun berbasis teknologi, dan begitupun banyak dilakukan oleh sebagian pelaku UMKM di Sentra Industri Sepatu Cibaduyut untuk mengakses informasi seputar pasar yang kirakira dapat dituju ataupun mengakses informasi lainnya yang memudahkan usaha pelaku UMKM disana.

\section{Kesimpulan}

Berdasarkan hasil pembahasan dalam penelitian ini dan juga merujuk pada tujuan penelitian, maka bisa disimpulkan kalau tidak ada pengaruh signifikan antara variabel orientasi kewirausahaan dan variabel kinerja pemasaran 
terhadap variabel keunggulan bersaing pada pelaku UMKM di Sentra Industri Sepatu Cibaduyut. Hal tersebut disebabkan oleh pandemi Covid-19 ini yang membuat para pelaku UMKM kebingungan dalam meningkatkan kembali performa usaha baik dari sisi produksi maupun dari pemasaran produknya.

Selanjutnya da pengaruh signifikan antara variabel kapabilitas TIK terhadap variabel keunggulan bersaing pada pelaku UMKM di Sentra Industri Sepatu Cibaduyut. Hal tersebut didukung dengan adanya kemampuan dan kemauan untuk mengakses informasi seputar pasar yang kira-kira dapat dituju ataupun mengakses informasi lainnya yang dapat menunjang dan memudahkan keberlangsungan usaha para pelaku UMKM di Sentra Industri Sepatu Cibaduyut.

Berdasarkan hasil kesimpulan di atas maka variabel Kapabilitas TIK yang memiliki pengaruh paling signifikan terhadap keunggulan bersaing sebesar $44.9 \%$. Namun untuk variabel lain yang mempengaruhi keunggulan bersaing tidak dibahas dalam penelitian ini.

\section{Daftar Pustaka}

Avlontis, G.J. \& Salavou, H.E. (2007). Entrepreneurial Orientation of SMES, Product Innovativeness, and Performance, Journal of Business Research, 60(5): 566575.

Cahyono, Budi. (2020). Imbas Corona, Omzet Usaha Sepatu di Cibaduyut Turun 100\% (online)https://www.ayojakarta.com/read/2 $\underline{020 / 04 / 18 / 15814 / \text { imbas-corona-omzet- }}$ usaha-sepatu-di-cibaduyut-turun-100 (diakses 31 Maret 2021).

Chin, W. W. (1998). The Partial Least Squares Approach to Structural Equation Modeling. Modern methods for business research, pp.295-335.

Deeson, E. (1991). Dictionary of Information Technology. Glasgow, UK: Harper Collins Publishers.

Dinas Perdagangan dan Perindustrian Kota Bandung. (2020). Jumlah Pelaku UMKM di Sentra Industri Sepatu Cibaduyut (online) http://disdagin.bandung.go.id/ (diakses 31 Maret 2021)

Drucker, Peter F. (1994). Innovation and Entrepreneurship, Practice and Principles. Jakarta: Gelora Aksar.

Febrantara, D. (2020). Bagaimana Penanganan
UKM di Berbagai Negara Saat Ada Pandemi Covid-19. (online) https://drive.google.com/drive/folders/1MY 31IOC3gWqEgzNkuJzqJnB9PV6qA2D (diakses pada 31 Maret 2021)

Ferdinand, Augusty. (2000). Manajemen Pemasaran: Sebuah Pendekatan Stratejik. Semarang: Program Magister Manajemen Universitas Diponegoro.

Ferdinand, Augusty. (2002). Kualitas Strategi Pemasaran: Sebuah Studi Pendahuluan. Jurnal Sains Pemasaran. 1(1)107-: 119.

Fiqih, Rizkya Putra. (2016). Identifikasi Lingkungan Internal dan Eksternal Dalam Strategi Pengembangan Usaha Pada Sentra Industri Sepatu Cibaduyut Kota Bandung. e-Proceeding of Management, 3(2): 14451452.

Ghozali, Imam. (2008). Structural Equation Medeling-Metode Alternatif dengan Partial Least Square. Semarang: Badan Penerbit Universitas Diponegoro.

Lumpkin \& Dess. 1996. Clarifying the Entrepreneurial Orientation Construct and Linking It to Performance. Journal of Academy Management Review, 21(1): 135139.

Malhotra, N. K. (2009). Riset Pemasaran Pendekatan Terapan. Jilid 1. Jakarta: Permata Puri Media.

Porter, Michael, E. (1994). The Competitive Advantage of Nations. London: The Mac Millan Press L.td

Sekaran, Uma. (2003). Research Methods for Business: A Skill Building Aproach. New York-USA: John Wiley and Sons, Inc.

Singh, R.K. (2011). Developing the Framework for Coordination in Supply Chain of SMEs, Business Process Management Journal, 17(4): 619-638.

Suryani, Evi. (2021). Analisis Dampak Covid-19 Terhadap UMKM (Studi Kasus: Home Industri Klepon Di Kota Baru Driyorejo). Jurnal Inovasi Penelitian, 1(8): 1591-1596.

Susilo, Sri Y. (2010). Strategi Meningkatkan Daya Saing UMKM dalam Menghadapi Implementasi CAFTA Dan MEA. Buletin Ekonomi, 8(2): 70.

Sutisna, Astri. (2012). Pengaruh Pelatihan Materi Sains Berbasis TIK Terhadap Peningkatan Scientific Literacy dan TIK Literacy Guru Sekolah Dasar. Bandung: Universitas 
Pendidikan Indonesia.

Tenenhaus M, Vinzi VE, Chatelin YM, Lauro C. (2005). PLS Path Modeling. Computational Statistics \& Data Analysis, 48(1): 159-205.

Ummi, Eva. (2015). Structural Equation ModelingPartial Least Square untuk Pemodelan Derajat Kesehatan Kabupaten/Kota di Jawa Timur (Studi Kasus Data Indeks Pembangunan Kesehatan Masyarakat Jawa Timur 2013). Jurnal Sains dan Seni, 4(2): 169-174.

Wibowo, Agung Raharjo. 2006. Analisis FaktorFaktor yang Mempengaruhi Inovasi Produk untuk Meningkatkan Keunggulan Bersaing dan Kinerja Pemasaran (Studi pada
Industri Batik Skala Besar dan Sedang di Kota dan Kabupaten Pekalongan). Semarang: Pascasarjana Universitas Diponegoro.

Zhang, M., Sarker, S., \& Sarker, S. (2008). Unpacking the effect of IT capability on the performance of exportfocused SMEs: a report from China. Information System Journal. 18(4): 357.

Zultaqawa, Zeis. (2020). Pengaruh Infrastruktur Teknologi Informasi, Aksesibilitas dan Mobilitas Terhadap Keunggulan Kompetitif Melalui Aksi Kompetitif pada Industri Pakaian di Kabupaten Bandung. Bandung: Pascasarjana Universitas Padjajaran. 